\title{
Associations between balance ability and dance performance using field balance tests
}

(Authors' proof for publication in Medical Problems of Performing Artists, 2019, 34(3), pp.154-160)

\section{Abstract}

Purpose: Although balance is a key element of dance, it remains to be confirmed which balance components are associated with dance performance. The aim of this study was to assess the associations between different field balance tests and dance performance in an inhouse measure in ballet, contemporary and jazz genres. Methods: 83 female undergraduate dance students $(20 \pm 1.5$ years; $163.04 \pm 6.59 \mathrm{~cm} ; 60.97 \pm 10.76 \mathrm{~kg})$ completed the Star Excursion Balance Test (SEBT), the Airplane test, a dance-specific pirouette test, the modified Romberg test, and the BioSway ${ }^{\mathrm{TM}}$ (Biodex, USA). The results from these balance tests were compared to the participants' technique and repertoire performance scores in ballet, contemporary, and jazz genres. Results: Ballet scores were best predicted by SEBT $90^{\circ}$ and Romberg for technique $(\mathrm{r}=0.4, \mathrm{p}=0.001$, SEE \pm 2.49$)$ and Romberg, SEBT $90^{\circ}$, and SEBT $225^{\circ}$ for repertoire $(r=0.51, p=0.001, S E E \pm 1.99)$. Contemporary data indicated SEBT $90^{\circ}$ and Romberg for technique $(r=0.37, p=0.001, \operatorname{SEE} \pm 2.67)$ and SEBT $225^{\circ}$ for repertoire $(r=0.27, p=0.015, \mathrm{SEE} \pm 2.29)$. Jazz indicated SEBT 90 ${ }^{\circ}$, Romberg, SEBT $315^{\circ}$, and SEBT $225^{\circ}$ for technique $(\mathrm{r}=0.51, \mathrm{p}=0.001, \mathrm{SEE} \pm 2.28)$ and SEBT $225^{\circ}$ and Romberg for repertoire $(r=0.41, p=0.001, S E E \pm 2.29)$. Conclusion: The present study suggests that balance ability has a limited influence on dance performance, with existing field balance tests demonstrating low to moderate associations with dance technique and repertoire.

\section{Introduction}

Balance has been suggested as a key skill for dance performance ${ }^{1,2,3}$, enabling the dancer to execute highly complex movements in a variety of choreographic styles and movement vocabulary in current repertoire ${ }^{4,5,6}$. Postural control during complex dance movements may be challenged by choreography ${ }^{7}$, particularly in theatrical dance repertoire which requires performers to have both technical expertise and aesthetic competence ${ }^{8}$. Balance is also a key factor in dance training ${ }^{3,9}$ and physical fitness ${ }^{10,11}$.

Associations between balance ability and selected performance measures have been reported in sport ${ }^{12}$. However, although the significance of elements such as muscular strength $^{13,14}$, aerobic power ${ }^{15,16}$, and overtraining ${ }^{17}$ have been studied in dancers, balance ability and its relation to theatrical dance performance remains unclear. Nevertheless, 
previous research has examined balance abilities relating to a number of factors, such as dancers' expertise ${ }^{18}$ which may affect postural control in certain conditions. For example, it has been argued that dancers develop specialist skills in regulating posture through visual feedback ${ }^{3,19,20}$; in fact, dancers' balance ability may decrease more significantly in closed eyes conditions compared to non-dancers ${ }^{19}$. This concurs with studies observing greater postural control with more complexity in dancers than other groups ${ }^{3,18,19}$, possibly due to dancers' flexibility in changing to different demands of postural control ${ }^{3}$. To date, the task difficulty of balance tests has varied in studies on dancers ${ }^{21}$ and some validated balance tests may not be challenging enough for expert dancers ${ }^{18,22}$.

Other studies have investigated dancers' balance ability in relation to aesthetic competence $^{23}$, fitness ${ }^{24}$, dancers' balance ability compared to non-dancers ${ }^{25,26}$, the effects of balance training on the performance of balance tests ${ }^{27}$, balance in relation to dance injury ${ }^{28}$, and age of dancers ${ }^{29}$, but, according to our knowledge, none have looked at theatrical dance performance thus far. For the purposes of the current study, dance is defined as theatrical dance, demonstrating a high level of skill, original form, and created for an audience ${ }^{30,31}$.

As indicated earlier, studies on balance in dancers demonstrate varying levels of balance task difficulty ${ }^{21}$. Another variation in the literature concerns the assessment tools used in tests. A systematic review of balance and theatrical dance revealed a variety of measurement tools used in balance studies ${ }^{21}$ Whilst the predominant measurement tool has been a force plate $2,21,25,32,33$, other studies used field tests such as the Star Excursion Balance Test (SEBT), a single-limb squat test with eight designated reach directions for the nonstance leg ${ }^{34,35,36}$, the Airplane test, a single-limb test with the torso and non-stance limb maintained in a horizontal position during flexion of the supporting $\operatorname{leg}^{37}$, dance-specific tests (eg., pirouettes, or single-limb turns) $)^{7,38,39}$ the Romberg test, a blindfolded single-limb static test $^{37}$, the Biodex Stability System, a single-limb static test ${ }^{26}$, the Balance Error Scoring System (BESS) ${ }^{34}$ and the Bass Test of Dynamic Balance (BASS) ${ }^{34}$. Performing the aforementioned field tests was regarded as within the reach of a dancer's skill base, with the exception of the dance-specific pirouette tests which is a more challenging balance task ${ }^{40}$.

To date, there is little replication of balance studies on dancers, and conflicting results may be linked to the considerable differences in testing apparatus ${ }^{21}$. Furthermore, although balance is often regarded as a key skill for dance performance, currently, there is no clear evidence for its support. Whilst tests have assessed either dynamic or static balance in different genres, no studies have investigated the predictive association of balance ability on dance performance. Therefore, the purpose of this study was to assess the associations 
between different balance field tests and technical and performance scores in ballet, contemporary and jazz genres.

\section{Methods}

\section{Participants}

A total of 83 female university dancers (age: $20 \pm 1.5$ years; height: $163.04 \pm 6.59 \mathrm{~cm}$; mass: $60.97 \pm 10.76 \mathrm{~kg}$; dance experience: $10.18 \pm 2.39$ years) volunteered for the study. All participants were enrolled in an undergraduate dance programme and received equal hours of training in contemporary, jazz and ballet. Inclusion criteria specified that they were 18 years of age or older, that they were injury free, and attended dance classes for a minimum of 8 hours per week. Participants completed a pre-activity health questionnaire prior to testing and those with a known illness including heart complaint, neuromuscular, and neurological disease, or taking medication that influences balance ability were excluded. The study was approved by the university ethics committee from the University of Wolverhampton.

Participants were informed verbally and in writing about the procedures and they signed an informed consent before they were included in the study.

\section{Procedures}

This cross-sectional study was designed to examine the association between balance ability and dance performance and compared results from five field balance tests to performance grades in three different dance genres (contemporary, ballet, and jazz). The dependent variables were the performance grades for contemporary, ballet, and jazz technique and repertoire assessments. The testing and grading protocols of the performance grades are well tested but not yet empirically validated. The independent variables were the balance tests: Star Excursion Balance Test (SEBT) ${ }^{34,35}$, Airplane ${ }^{37}$, Pirouettes ${ }^{38,39,40}$, Biosway ${ }^{26}$ and Romberg $^{37,41}$.

All participants completed a 15-minute standardised warm up session prior to data collection. The warm up consisted of pulse raising activities, joint mobilisation exercises and dynamic stretches. The same examiner demonstrated the movements of each of the tests and conducted all the tests for all participants. Leg length was measured from the anterior superior iliac spine to the medial malleolus ${ }^{42}$ The testing order of the balance tests was randomised; the order of the supporting limb was randomised in each test. Sample size was calculated using previously reported data ${ }^{43}$ assuming an $80 \%$ power with an alpha level of 5\%; a sample of 30 participants was required. Therefore the sample size of this study $(n=83)$ allowed appropriate regression analysis. 


\section{Field tests}

Five field balance tests were selected for the study; three for assessing dynamic balance [i.e., the Star Excursion Balance Test (SEBT) ${ }^{35}$, the Airplane Test ${ }^{37}$, and a dance-specific pirouette test $^{38,39,40}$ ] and two tests for evaluating static balance [i.e., the modified Romberg test ${ }^{37,41}$, and the Biosway (Biodex Medical Systems Inc, New York, USA) ${ }^{26}$ ]. The same testers observed all the tests ensuring adherence to test protocols, and collected all the data for the study.

The SEBT has shown acceptable interrater reliability of ICC $=0.86-0.92^{44}$, and consists of a series of single-leg balances standing on a grid comprising 8 lines marked on the floor, extending from a common point at $45^{\circ}$ angle increments. Prior to testing, the SEBT protocol was demonstrated by the researcher and participants performed practice trials to ensure accuracy in alignment and foot placement before the reaching distances were measured. The average of three trials was taken. Participants performed a single-leg squat with the standing foot aligned to the centre of the 8-line star while the non-weight bearing leg reached out as far as possible along a designated line ${ }^{44}$. The reaching directions are referenced according to the supporting leg as anterior $\left(0^{\circ}\right)$, anteromedial $\left(45^{\circ}\right)$, medial $\left(90^{\circ}\right)$, posteromedial $\left(135^{\circ}\right)$, posterior $\left(180^{\circ}\right)$, posterolateral $\left(225^{\circ}\right)$, lateral $\left(270^{\circ}\right)$, and anterolateral $\left(315^{\circ}\right)$. Leg reach distances were measured $(\mathrm{cm})$ for each reach direction. The reach distances in each direction were normalised to $\%$ leg length ${ }^{34}$. Termination of tests criteria were: displacement of the supporting foot, or weight placed on the reach foot ${ }^{42}$.

The Airplane test has been determined by a previous study as a reliable indicator of a dancer's skill level during pre-pointe training ${ }^{37}$. It is a single-leg balance test starting with the trunk flexed at $90^{\circ}$, the non-supporting leg extended to the back creating a horizontal line with the torso parallel to the floor, and the arms abducted to $90^{\circ 37}$. Participants performed five bends of the supporting leg with the arms adducted horizontally in order to touch the floor with the fingertips ${ }^{37}$ and horizontally abducting the arms when the support leg straightened to the start position. The number of times the fingertips touched the floor was recorded up to, and including, five instances. The termination test criterion was pronation of the supporting foot, knee valgus, hip adduction, hip internal rotation, or pelvic drop ${ }^{37}$.

Pirouettes are a recognised dance-specific balance test with en dehors turns being most widely used ${ }^{38,39,40}$ but to date, no pirouette tests have been empirically validated to our knowledge $^{21}$. In the lab-based pirouette test, six single pirouettes en dehors, were performed consecutively, starting from and returning to, an open turned out position of the feet with one foot crossed in front of the other $\left(4^{\text {th }}\right.$ position). The series of pirouettes were performed on the right and left leg in a randomised order. During the pirouette both legs were rotated outwards, 
with the non-supporting leg bent with a $90^{\circ}$ angle at the knee joint, and toes in contact and placed in front of the knee of the supporting leg (retiré). Pirouettes en dehors were conducted on the ball of the foot (demi pointe) with the arms held in front (1st position) during the rotation. The participants wore soft, thin-soled ballet shoes. The timing of the sequential turns replicated a common tempo used in Intermediate level ballet classes. At the start of the test, participants placed the ball (head of the metatarsals) of their front foot on the marker on the floor. At the end of the sixth turn, the position of the ball of the front foot was marked and the displacement distance $(\mathrm{cm})$ from the start mark to the finish mark was obtained. Termination of test criteria were the non-supporting foot touching the floor during a turn, and inaccurate placement of feet in the turn preparation position.

The Romberg test is routinely used in neurology ${ }^{41}$ to assess proprioceptive loss and there have been a number of modifications over the years. The modified Romberg test used in this study is a single-leg balance in a parallel stance ${ }^{37,41}$. Participants performed it with the non-supporting leg slightly bent and not touching the supporting leg. Arms were crossed across the chest and a blindfold was worn ${ }^{37,45}$. The duration of balance was recorded in seconds. Typically tested for 30 seconds $^{37}$, sustained balances were recorded up to a minute due to participants' ability and age. Termination test criteria were the non-supporting foot touching the floor and displacement of the supporting foot.

The BioSway (Biodex Medical Systems Inc, New York, USA) ${ }^{26}$ has shown acceptable intratester reliability of ICC $=0.82-0.43$ for stability index and ICC $=0.81-0.55$ for foot placement, with the overall stability index scores showing the most reliable stability scores $\left(0.82\right.$ for intratester and 0.70 for intertester ${ }^{46}$. These postural stability tests were conducted in single-leg stance. Participants were barefoot and asked to step onto the platform placing their arms in a neutral position. Foot position coordinates marked out on the platform were maintained for the supporting foot throughout all the trials. Participants were asked to look ahead and keep their eyes open. Participants performed three trials of 20 seconds on each leg. Data recorded postural stability (overall stability, anterior/posterior and medial/lateral). Data were excluded if the non-supporting foot was put down, or if the supporting foot moved.

\section{Performance grades}

Technique and repertoire grades were utilised for dance performance scores. As stated earlier, the testing and grading protocols of the performance grades are well used but not yet empirically validated. The collection of data met guidelines for reducing study limitations and risk of bias ${ }^{47}$. Assessors and participants were blinded to the use of performance grades 
thus reducing performance bias ${ }^{48}$, and detection bias ${ }^{48}$. The department's procedures for marking dance performance and accuracy in moderating grades meet the UK Benchmarks for the Performing Arts in Higher Education Institutions (HEIs), and have been recognised as exemplary for over 15 years in External Examiners' Reports received by the university's Quality Department. External Examiners in UK HEIs are selected for their expertise in their subject and have to meet exacting criteria for selection. All practical assessments were assessed in live performance and filmed for further analysis if required. All participants performed the same number of repetitions of exercises in technique or repertoire sequences as required by the assessors.

Repertoire can be defined as the body of pieces which are regularly performed. Contemporary technique comprised of movements from the codified techniques of Martha Graham and Merce Cunningham, and jazz technique comprised of the codified styles of Matt Mattox and lyrical jazz. Ballet repertoire was taken from two modern ballets by Maurice Bejart, contemporary repertoire was taken from works by Graham, Cunningham, Doris Humphrey and Twyla Tharp, jazz repertoire was taken from works by Bob Fosse and Michael Bennett. Assessment criteria for technique and repertoire grades were based on the following components: technical skills, musicality, spatial awareness, dynamic range, artistry and, for the repertoire, interpretation of the role. The criteria had been agreed by Department members and accepted by the External Examiner for the university dance programme.

For all the assessments, the grades were agreed by the independent assessors within one mark to be accepted as accurate and meeting benchmark criteria. Grade descriptors were adhered to in moderation meetings, and the grades given adhered to the university marking requirements. The university descriptions of the mark ranges were as follows: Retrievable Fail: 32-39\%, Satisfactory (Pass): 40-49\%, Good: 50-59\%, Very Good: 60-69\%, Excellent: 70-79\%, Outstanding: 80-89\%, Exceptional: 90-100\%. The assessments were blind marked by two lecturers from the Dance Department, moderated by a third marker from the same Department, and accepted by the university exam board. The assessors and participants were blinded to the aims of the present study.

\section{Statistical Analyses}

Step-wise regression analysis was conducted to detect which balance tests best predicted performance ability. The dependent variables were the performance grades for the ballet, contemporary and jazz technique and repertoire assessments. The independent variables were the balance tests (SEBT, Airplane, Pirouettes, Biosway and Romberg). Balance variables 
were gradually eliminated until only data of significance remained. Statistical significance was set at $\mathrm{p}<0.05$ using the SPSS 20 (IBM Corporation, Chicago, Ill).

\section{Results}

The mean and standard deviation data for the performance grades and balance tests scores showed variability for SEBT (left leg) and SEBT (right leg). Variability was shown also in the mean and SD data for Romberg, Airplane, Biosway, and Pirouette with examples of higher SD for the Pirouette tests across all genres in technique and repertoire.

The variables that were best associated with ballet technique performance grades were the leg reach in SEBT $90^{\circ}$ and the Romberg test $(r=0.4, p=0.001$ SEE \pm 2.49$)$. The variables that best predicted contemporary technique performance grades were the leg reach in SEBT $90^{\circ}$ and the Romberg test $(r=0.366, p=0.001 \mathrm{SEE} \pm 2.67)$. A greater number of variables were best associated with jazz technique performance: the leg reach in SEBT 90 $0^{\circ}$ SEBT $315^{\circ}$, and SEBT $225^{\circ}$, and the Romberg test, ( $\left.\mathrm{r}=0.507, \mathrm{p}=0.001 \mathrm{SEE} \pm 2.28\right)$ (Table 1).

TABLE 1. Variables that best predicted technique and repertoire performance grades

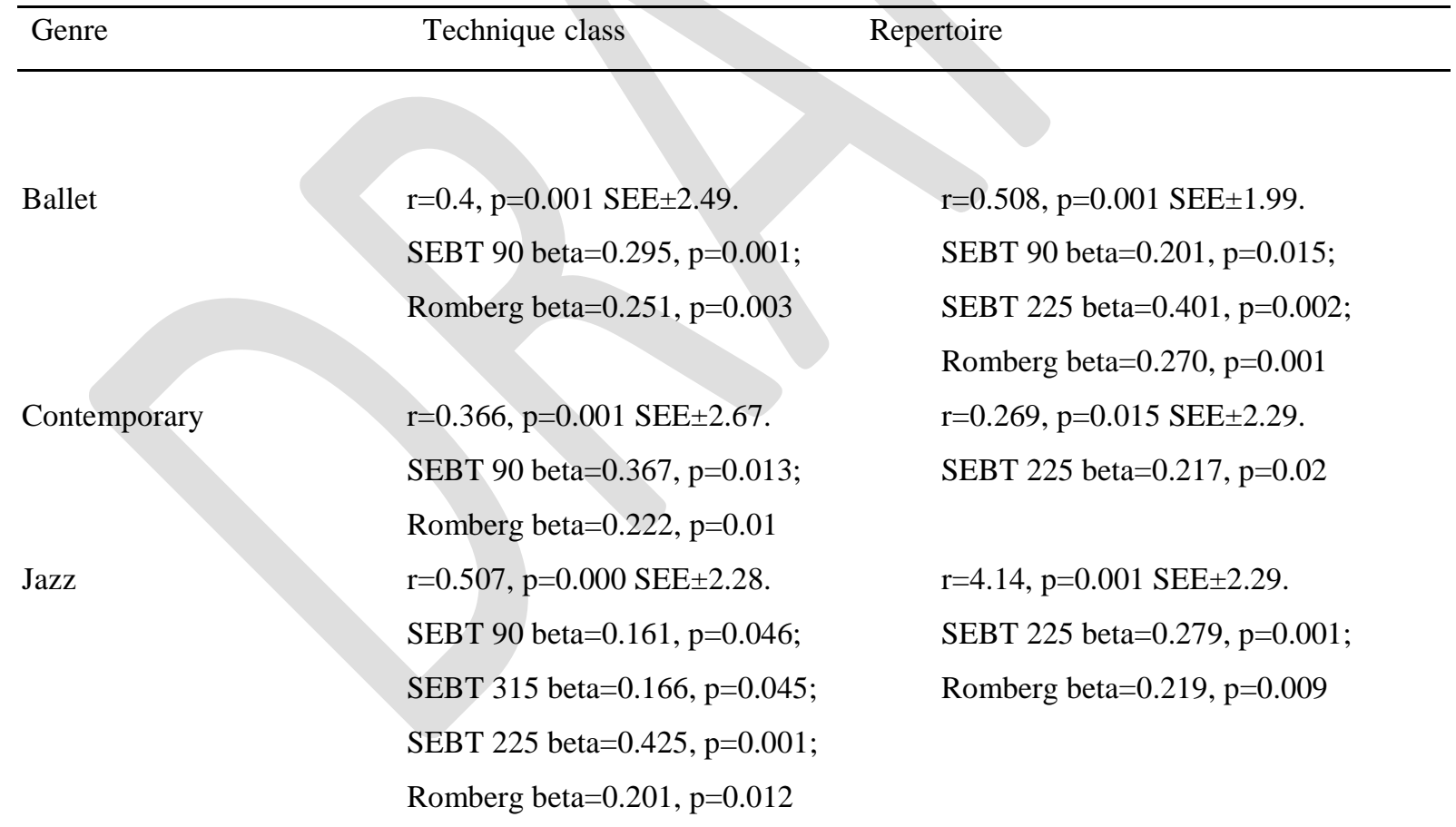

Star Excursion Balance Test $\left(\right.$ SEBT):SEBT $90=$ medial $\left(90^{\circ}\right)$, SEBT $225=$ posterolateral $\left(225^{\circ}\right)$, SEBT $315=$ anterolateral $\left(315^{\circ}\right)$. Note: the reaching directions are referenced according to the supporting leg.

Similarly, a number of variables associated with repertoire performance grades. The variables that best predicted ballet repertoire performance grades were: the leg reach in SEBT 
$90^{\circ}$, and in SEBT $225^{\circ}$, and the Romberg test $(\mathrm{r}=0.508, \mathrm{p}=0.001, \mathrm{SEE} \pm 1.99)$. The variables that best predicted contemporary repertoire grades were: the leg reach in SEBT $225^{\circ}$ $(\mathrm{r}=0.269, \mathrm{p}=0.015 \mathrm{SEE} \pm 2.29)$. The variables that best predicted jazz repertoire grades were: the leg reach in SEBT $225^{\circ}$ and the Romberg test ( $\left.\mathrm{r}=0.414, \mathrm{p}=0.001, \mathrm{SEE} \pm 2.29\right)$ (Table 1).

Variance was calculated: $16 \%$ of the factors that determined ballet technique performance also determined SEBT $90^{\circ}$ and Romberg scores $\left(\mathrm{F}_{(3,124)}=7.894, \mathrm{p}=.001\right)$ with an $\mathrm{R}^{2}$ of $.160 ; 13.4 \%$ of the factors that determined contemporary technique performance also determined SEBT $90^{\circ}$ and Romberg scores $\left(\mathrm{F}_{(3,124)}=6.407, \mathrm{p}=.001\right)$ with an $\mathrm{R}^{2}$ of .134; $25.8 \%$ of the factors that determined jazz technique performance also determined SEBT $90^{\circ}$, SEBT $315^{\circ}$, SEBT $225^{\circ}$, and Romberg scores $\left(\mathrm{F}_{(4,123)}=10.666, \mathrm{p}=.001\right)$ with an $\mathrm{R}^{2}$ of .258 . For repertoire performance, $25.8 \%$ of the factors that determined ballet repertoire performance also determined SEBT $90^{\circ}$ and Romberg scores $\left(\mathrm{F}_{(4,123)}=10.691, \mathrm{p}=.001\right)$ with an $\mathrm{R}^{2}$ of $.258 ; 7.2 \%$ of the factors that determined contemporary repertoire performance also determined SEBT $225^{\circ}$ scores $\left(\mathrm{F}_{(2,111)}=4.327, \mathrm{p}=.015\right)$ with an $\mathrm{R}^{2}$ of .072 ; and $17.1 \%$ of the factors that determined jazz repertoire performance also determined SEBT $225^{\circ}$ and Romberg scores $\left(\mathrm{F}_{(3,124)}=8.526, \mathrm{p}=.001\right)$ with an $\mathrm{R}^{2}$ of .171 .

\section{Discussion}

The aim of this study was to examine the association between balance ability and dance performance, with particular reference to the genres of ballet, contemporary and jazz. The present study was the first to examine balance ability as an indicator of performance in theatrical dance. Our results suggest that some balance tests indicated predictive ability on dance performance (technique and repertoire) in all three genres (Table 1). However, the prediction strength of these balance assessment tools was relatively low. Within this framework, the Romberg was the predominant predictor of successful performance, indicating an association with all of the dependant variables, except contemporary repertoire; it is noteworthy that this was the only test performed with eyes closed. However, we cannot ascertain the causes of the association between the Romberg and dance performance from these results. Evidence on dancers' balance abilities when visual information is removed remains inconclusive. The dependence of dancers on visual information for regulation of postural control has been previously identified ${ }^{19,25}$, where a decrease in balance performance in eyes closed conditions has been found possibly because dance classes and performances do not demand balance ability with eyes closed $^{22}$; in these eyes closed conditions a shift from visual to somatosensory information has been identified ${ }^{49,50}$, particularly in dynamic balance 
$\operatorname{tasks}^{49}$. In static, balance tasks with eyes open/closed, dancers relied more on visual information than somatosensation, displaying better balance in eyes open conditions ${ }^{2,25}$, and worse balance than controls and judoists when visual information was removed ${ }^{25}$. In contrast, dancers demonstrated better balance abilities than non-dancers in eyes closed timed static balances $^{51}$. Furthermore, pre-professional dancers showed improvement in some timed balance tests, measured in time and distance, following an eyes closed balance intervention programme ${ }^{52}$. A study on brain structure and function revealed that dancers' balance performance was not related to their dance training compared to non dancers ${ }^{53}$, and that dancers may have reached a ceiling for their balance performance. In contrast, when visual information is removed, dancers may face more challenging tasks to maintain postural stability $^{2,25,50}$.

The other most common predictors of successful performance were two reach distances in the SEBT: the SEBT $90^{\circ}$ and SEBT $225^{\circ}$ (Table 1). The regression between the ballet, contemporary and jazz technique scores and SEBT $90^{\circ}$ results may indicate a learning effect from their training in those genres as both use extended lines to the side $\left(90^{\circ}\right)$. This concurs with published data whereby dancers may have had more practice in certain reach directions in the SEBT due to their dance participation ${ }^{34}$. The correlation found between SEBT $225^{\circ}$ and the repertoire scores in ballet, contemporary and jazz may reflect a balance strategy using the torso to counterbalance ${ }^{9}$. Although the posterolateral reach distance $\left(225^{\circ}\right)$ is less prevalent in codified technique training, the repertoire pieces in the three dance genres were demanding in both spatial components and aesthetic competence.

A number of balance tests (Airplane, pirouette, Biosway, SEBT reach directions $\left(0^{\circ}\right.$, $45^{\circ}, 135^{\circ}, 180^{\circ}, 270^{\circ}$ ) did not demonstrate any predictive power for dance performance. Research has shown that balance tests do not necessarily produce demands which are challenging enough for dancers ${ }^{18,53}$, and to date, there is limited evidence for the relevance of these balance tests in dancers due to an absence of replicated studies ${ }^{21}$ and study limitations ${ }^{21,48}$. Nevertheless, pirouettes are regarded as a more challenging balance task for dancers $^{40,54}$ requiring postural adaptations for successful rotations ${ }^{54}$. In the future, pirouette test protocols tested for validity and reliability with subsequent replication may reveal different results, albeit with limitations already discussed .The highest regression scores were shown between SEBT $90^{\circ}$, SEBT $225^{\circ}$ and Romberg and the ballet repertoire scores, suggesting that these balance tests should be considered in future research. However, it must be noted that whilst these tests were predictors of ballet repertoire performance (25.8\%), and jazz technique $(25.8 \%)$, these values are relatively low, and they demonstrated weaker 
associations with contemporary technique and repertoire. Thus, their predictive ability for different dance genres remains unclear. Whilst our results indicate that certain balance tests have low to moderate predictive ability on dance technique and repertoire, further interventional investigation in this area is recommended.

\section{Strengths and limitations}

The present findings constitute a positive contribution to the existing body of knowledge as no such study on associations between balance ability and dance performance has been previously conducted. Another strength of this work is the detailed description of the methodology in line with GRADE guidelines with recommendations for researchers to reduce study limitations ${ }^{48}$.

However, it is reasonable to assume that the present results may have been influenced by some methodological limitations. The grading of performance marks assessed optimal dance performance in an in-house measure which has not been empirically validated to date, but this protocol could be an opportunity for further research. Whilst pirouettes have been recognised as a functional, dance-specific balance test in a number of studies, this assessment tool has not been empirically validated but may merit further investigation. Participants demonstrated varied experience in the technical demands of the dance-specific pirouette test, and a few participants exhibited occasional weakness in alignment when executing a series of single pirouettes during testing. In addition, reach distances in the SEBT may have been limited to participants' own exertion and interpretation of the given instructions. The examination of performance scores has been limited to those in theatrical dance.

\section{Conclusion}

This study is the first to assess associations between balance ability and dance performance scores. Within its limitations, the present study indicates low to moderate associations between balance, dance technique, and repertoire performances, thus challenging the traditionally held perception of the importance of balance ability for optimal dance performance in an in-house measure. The regression between the SEBT $90^{\circ}$, SEBT $225^{\circ}$, and Romberg and ballet repertoire revealed the strongest association between balance tests and dance performance. Although our findings indicate that both static and dynamic balance ability may be of benefit to dance performance, the predictive ability was moderately low and the SEBT reach directions $\left(90^{\circ}, 225^{\circ}\right)$ appear to be random. Further development of dancespecific balance tests is suggested in order to advance the predictive ability of balance tests on dance performance.

\section{References}


1. Costa MSS, Ferreira AS, Felicio LR. Static and dynamic balance in ballet dancers: a literature review. Fisioter Pesq 2013;20(3):292-298. doi: 10.1590/S180929502013000300016

2. Hugel F, Cadopi M, Kohler F, Perrin P. Postural control of ballet dancers: a specific use of visual input for artistic purposes. Int J Sports Med 1999;20(2):86-92. doi: $10.1055 / \mathrm{s}-2007-971098$

3. Schmit JM, Regis DI, Riley MA. Dynamic patterns of postural sway in ballet dancers and track athletes. Exp Brain Res 2005;163:370-378. doi: 10.1007/s00221-0042185-6

4. Redding E, Wyon M. Strengths and weaknesses of current methods for evaluating the aerobic power of dancers. J Dance Med Sci 2003;7(1):10-16.

5. Twitchett E, Angioi M, Koutedakis Y, Wyon M. Video Analysis of Classical Ballet Performance. J Dance Med Sci 2009;13(4):124-128.

6. Wyon MA, Twitchett E, Angioi M, Clarke F, Metsios G, Koutedakis Y. Time Motion and Video Analysis of Classical Ballet and Contemporary Dance Performance. Int J Sports Med 2011;32(11):851-855. doi: 10.1055/s-0031-1279718

7. Zaferiou AM, Wilcox RR, McNitt-Gray JL. Whole-body balance regulation during the turn phase of pique and pirouette turns with varied rotational demands. Med Probl Perform Art 2016;31(2):96-103. doi: 10.21091/mppa.2016.2017

8. Jarvis DN, Smith JA, Kulig K. Trunk coordination in dancers and nondancers. J Appl Biomech 2014;30:547-554. doi: 10.1123/jab.2013-0329

9. Batson G. Validating a dance-specific screening test for balance. Preliminary results from multisite testing. Med Probl Perform Art 2010;25(3):110-115.

10. Koutedakis Y, Jamurtas A. The dancer as a performing athlete. Sports Med 2004;34(10):651-661. doi: 10.2165/00007256-200434100-00003

11. Koutedakis Y, Hukam H, Metsios G, Nevill A, Giakas G, Jamurtas A, Myszkewycz L. The effects of three months of aerobic and strength training on selected performance- and fitness-related parameters in modern dance students. J Strength Cond Res 2007;21(3):808-812. doi: 10.1519/R-20856.1

12. Hrysomallis C. Balance ability and athletic performance. Sports Med 2011;41(3): 221-232. doi.org/10.2165/11538560000000000-00000

13. Koutedakis Y, Stavropoulos-Kalinoglou A, Metsios G. The significance of muscular strength in dance. J Dance Med Sci 2005;9(1):29-34.

14. Twitchett E, Brodrick A, Nevill AM, Koutedakis Y, Angioi M, Wyon M. Does physical fitness affect injury occurrence and time loss due to injury in elite vocational ballet students? J Dance Med Sci 2010;14(1):26-31.

15. Twitchett E, Nevill A, Angioi M, Koutedakis Y, Wyon M. Development, validity, and reliability of a ballet-specific aerobic fitness test. J Dance Med Sci 2011;15(3):123-127.

16. Wyon M, Allen N, Cloak R, Beck S, Davies P, Clarke F. Assessment of maximum aerobic capacity and anaerobic threshold of elite ballet dancers. Med Probl Perform Art 2016;31(3):145-149.

17. Koutedakis Y. "Burnout" in dance; the physiological viewpoint. J Dance Med Sci 2000;4(4):122-127. 
18. Stins JF, Michielsen ME, Roerdink M, Beek PJ. Sway regularity reflects attentional involvement in postural control: Effects of expertise, vision and cognition. Gait Posture 2009;30:106-109.doi: 10.1016/j.gaitpost.2009.04.001

19. Pérez RM, Solana RF, Murillo DB, Hernández FJM. Visual availability, balance performance and movement complexity in dancers. Gait Posture 2014;40(4):556-560. doi: 10.1016/j.gaitpost.2014.06.021

20. Golomer E, Mbongo F, Toussaint Y, Cadiou M, Israël I. Right hemisphere in visual regulation of complex equilibrium: the female ballet dancers' experience. Neurol Res 2010;32(4):409-415. doi: 10.1179/174313209X382476

21. Clarke F, Koutedakis Y, Wilson M, Wyon M. Balance in theatrical dance performance: A systematic review. Med Probl Perform Art 2018;33(4):276-286. doi.org/10.21091/mppa.2018.4041

22. Gerbino PG, Griffin ED, Zurakowski D. Comparison of standing balance between female collegiate dancers and soccer players. Gait Posture 2007;26:501-507. doi: 10.1016/j.gaitpost.2006.11.205

23. Angioi M, Metsios G, Twitchett E, Koutedakis Y, Wyon M. Association between selected physical parameters and aesthetic competence in contemporary dancers. $J$ Dance Med Sci 2009;13(4):115-123.

24. Strešková E, Chren M. Balance ability level and sport performance in Latin-American dances. Phys Ed Sport 2009;7(1):91-99.

25. Perrin P, Deviterne D, Hugel F, Perrot C. Judo, better than dance, develops sensorimotor adaptabilities involved in balance control. Gait Posture 2002;15:187-194. doi: 10.1016/S0966-6362(01)00149-7

26. Rein S, Fabian T, Zwipp H, Rammelt S, Weindel S. Postural control and functional ankle stability in professional and amateur dancers. Clin Neurophysiol 2011;122(8):1602-1610. doi: 10.1016/j.clinph.2011.01.004

27. Watson T, Graning J, McPherson S, Carter E, Edwards J, Melcher I, Burgess T. Dance, balance and core muscle performance measures are improved following a 9-week core stabilization training program among competitive collegiate dancers. Int J Sports Phys Ther 2017;12(1):25-41.

28. Clark T, Redding E. The relationship between postural stability and dancer's past and future lower-limb injuries. Med Probl Perform Art 2012;27(4):197-204.

29. McKinley P, Jacobson A, Leroux A, Bednarczyk V, Rossignol M, Fung J. Effect of a community-based Argentine tango dance program on functional balance and confidence in older adults. J Aging Phys Activity 2008;16(4):435-453. doi: 10.1123/japa.16.4.435

30. Martin J. Introduction to the Dance. New York: Dance Horizons, 1965

31. Paskevska A. Ballet beyond tradition. New York: Routledge, 2005

32. Pappas E, Kremenic I, Liederbach M, et al. Time to stability differences between male and female dancers after landing from a jump on flat and inclined floors. Clin J Sport Med 2011;21(4):325-329. doi: 10.1097/JSM.0b013e31821f5cfb

33. Wyon MA, Cloak R, Lucas J, et al. Effect of midsole thickness of dance shoes on dynamic postural stability. Med Probl Perform Art 2013;28(4):195-198. 
34. Ambegaonkar JP, Caswell SV, Winchester JB, Shimokochi Y, Cortes N, Caswell AM. Balance comparisons between female dancers and active nondancers. Res Q Exerc Sport 2013;84:24-29. doi: 10.1080/02701367.2013.762287

35. Gribble PA, Hertel J, Plisky P. Using the Star Excursion Balance Test to assess dynamic postural-control deficits and outcomes in lower extremity injury: A literature and systematic review. J Athl Train 2012;47(3):339-357. doi.org/10.4085/1062-605047.3.08

36. Cloak R, Nevill AM, Clarke F, et al. Vibration training improves balance in unstable ankles. Int J Sports Med 2010;31:894-900. doi: 10.1055/s-0030-1265151

37. Richardson M, Liederbach M, Sandow E. Functional criteria for assessing pointereadiness. J Dance Med Sci 2010;14(3):82-88.

38. Denardi RA, Ferracioli MC, Rodrigues ST. Informação visual e control postural durante a execução da pirouette no ballet. Rev Port Cien Desp 2008;8(2):241-250.[Visual information and postural control during pirouette execution in ballet] Portuguese

39. Golomer EME, Gravenhorst RM, Toussaint Y. Influence of vision and motor imagery styles on equilibrium control during whole-body rotations. Somatosens Mot Res 2009b;26(4):105-110. doi: 10.3109/08990220903384968

40. Lin C-W, Chen S-J, Su F-C, et al. Differences of ballet turns (pirouette) performance between experienced and novice ballet dancers. Res Q Exerc Sport 2014b;85:330-340. doi: 10.1080/02701367.2014.930088

41. Rogers JH. Romberg and his test. J Laryngol Otol 1980;9:1401-1404. doi.org/10.1017/S002221510009023X

42. Kinzey SJ, Armstrong CW. The reliability of the Star-Excursion Test in assessing dynamic balance. J Orthop Sports Phys Ther 1998;5(1):61-70. doi:10.2519/jospt.1998.27.5.356

43. Mertz L, Docherty C. Self-described differences between legs in ballet dancers. Do they relate to postural stability and ground reaction force measures? J Dance Med Sci 2012;16(4):154-160

44. Gribble PA, Kelly SE, Refshauge KM, Hiller CE. Interrater reliability of the star excursion balance test. J Athl Train 2013;48(5):621-626. doi.org/10.4085/1062-605048.3.03

45. Khasnis A, Gokula RM. Romberg’s test. J Postgrad Med 2003;49(2):169-172.

46. Schmitz RJ, Arnold BL. Intertester and intratester reliability of a dynamic balance control using the Biodex Stability System. J Sport Rehabil 1998;7(2):95-101. doi: 10.1123/jsr.7.2.95

47. Guyatt GH, Oxman AD, Vist G, et al. GRADE guidelines: 4. Rating the quality of evidence-study limitations (risk of bias). J Clin Epidemiol 2011b;64:407-415. doi: 10.1016/j.clinepi.2010.07.017

48. Meader N, King K, Llewellyn A, et al. A checklist designed to aid consistency and reproducibility of GRADE assessments: development and pilot validation. Syst Rev 2014;3:82. doi: 10.1186/2046-4053-3-82

49. Golomer E, Dupui P. Spectral analysis of adult dancers' sways: sex and interaction vision-proprioception. Int J Neurosci 2000;105:15-26. doi:

10.3109/00207450009003262 
50. Simmons RW. Sensory organization determinants of postural stability in trained ballet dancers. Int J Neurosci 2005;115:87-97. doi: 10.1080/00207450490512678

51. Crotts D, Thompson B, Nahom M, Ryab S, Newton RA. Balance abilities of professional dancers on select balance tests. J Orthop Sports Phys Ther 1996;3(1):1217. doi: 10.2519/jospt.1996.23.1.12

52. Hutt K, Redding E. The effect of an eyes-closed dance-specific training program on dynamic balance in elite pre-professional ballet dancers:A randomized controlled pilot study. J Dance Med Sci 2014;18(1):3-11. doi.org/10.12678-313X.18.1.3

53. Burzynska AZ, Finc K, Taylor BK, Knecht AM, Kramer AF. The dancing brain: Structural and functional signatures of expert dance training. Front Hum Neurosci 2017;11:1-20. doi: 10.3389/fnhum.2017.00566.

54. Lott MB, Laws KL. The physics of toppling and regaining balance during a pirouette. $J$ Dance Med Sci 2012;16(4):167-174. 
TABLE 1. Variables which best predicted technique and repertoire performance grades

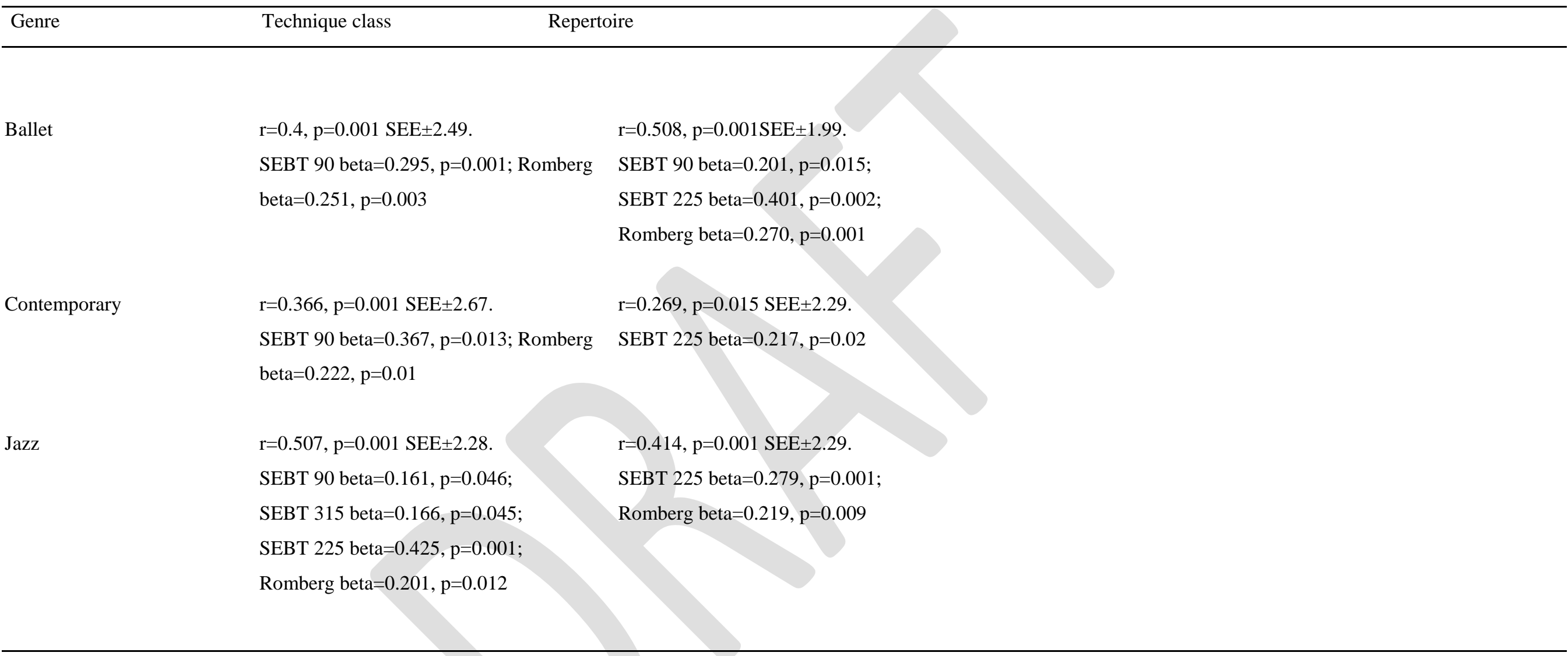

Star Excursion Balance Test $(\mathrm{SEBT})$ :SEBT $90=$ medial $\left(90^{\circ}\right)$, SEBT $225=$ posterolateral $\left(225^{\circ}\right)$, SEBT $315=$ anterolateral $\left(315^{\circ}\right)$. Note: the reaching directions are referenced according to the supporting leg 


$$
\text { से }
$$

